\title{
NOTICIAS DE JUAN RECIO DE LEÓN, DESCUBRIDOR Y REPOBLADOR EN TIPUANE, CHUNCHOS Y PAITITE (actual Bolivia)
}

News from Juan Recio de León, Discoverer and Settler of Tipuane, Chunchos and Paitite (modern day Bolivia)

Ignacio Arellano*

Resumen

Este artículo ofrece una aproximación a la figura de Juan Recio de León, descubridor y repoblador de las zonas de Tipuane, Chunchos y Paitite y a sus memoriales entre los que destaca la Relación de los servicios que Juan Recio de León... ha hecho a su majestad de más de veinte años a esta parte y la Breve relación, ambos documentos de 1623. Estos dos textos resultan de especial interés por las noticias que aportan sobre la flora, fauna y costumbres de los indios.

Palabras clave: Juan Recio de León, Memoriales, Crónicas de Indias.

Abstract

The article offers an approximation to the figure of Juan Recio de León, discoverer and settler of Tipuane, Chunchos and Paitite, and to his memorials, particularly his Relación de los servicios que Juan Recio de León... ha hecho a su majestad de más de veinte años a esta parte and Breve relación, both of 1623 . These texts have special interest because of the information that they present about the flora, fauna and the customs of the natives.

Key words: Juan Recio de León, Memorials, Chronicles of the Indies.

\section{PERFIL BIOGRÁFICO DE JUAN RECIO DE LEÓN}

Los escasos datos biográficos de Juan Recio de León, “aventurero nato y grafómano empedernido" (Barnadas, 2008:215), que han llegado hasta nosotros proceden de sus propios memoriales, especialmente de la Relación de los servicios que Juan Recio de León... ha hecho a su Majestad de más de veinte años a esta parte, documento de $1623,{ }^{1}$ en el que el antiguo maestre de campo presenta a Felipe IV un resumen cronológico de sus principales trabajos. Carecemos de detalles personales, familiares o íntimos de su infancia, formación, ámbito doméstico, etc., aspectos improcedentes en el tipo de textos memorialísticos en los que fue consignando incansablemente sus empresas de descubrimiento, pacificación,

\footnotetext{
${ }^{1}$ La datación de 1625 que se le atribuye, por ejemplo, en la monumental y admirable Bibliotheca boliviana antiqua de Barnadas (núm., 286), procede de la fecha de las resoluciones del Consejo añadidas al documento de Recio: hay tres, fechadas en 14 de julio de 1623, 25 de octubre de 1624 y 23 de junio de 1625, rechazando las pretensiones de Recio. Sólo la última resolución es de 1625. En el impreso no se distinguen gráficamente del texto del propio Recio, así que el error es muy fácil. Para este perfil biográfico recurro fundamentalmente a este documento. Luego añadiré otros detalles.
} 


\section{Ignacio Arellano}

organización y repoblación en distintos lugares de las Indias a lo largo de veinte años, y solicitando, sin éxito, las recompensas a las que aspiraba.

Si damos fe a los hechos que cuenta (no hay por qué negarla, aunque se maticen sus valoraciones), Juan Recio nace en la villa de Vega de Rioponce, en el reino de León. Comenzó sus servicios en la armada bajo el mando del general Luis Fajardo, quien gobernó la escuadra que en 1605 expulsó a los holandeses que merodeaban las salinas de Punta Araya, cerca de Cumaná, en Venezuela. Como dato curioso señalaré que en esta escuadra iba la monja alférez, Catalina de Erauso, ${ }^{2}$ que quince años más tarde encontrará de nuevo Recio de León en las guerras de Chile, y llevará en su compañía a otras empresas de los reinos del Perú, sin conocer su identidad femenina.

Tras dos años en la armada sienta plaza con el capitán don Pedro Berbegal, que en 1606 levantaba gente para los galeones de la carrera de Indias. Enferma en Cartagena, "y habiendo tenido noticia de un tío suyo que estaba en el Nuevo Reino de Granada, se fue a su casa". En 1607 le da su tío alguna hacienda, que emplea en la conquista de los indios pijaos, "y en otra ocasión para la de los indios carares y areguíes del río grande de la Magdalena". No olvida señalar que todo esto se hace sin gasto de los dineros de la Corona, un motivo recurrente en todos sus escritos. Desempeña (1614) por nombramiento del presidente y cabildo de Santa Fe de Bogotá el cargo de alcalde de la Santa Hermandad para reprimir los numerosos delincuentes que hacían difícil la vida en los caminos y haciendas del campo, "gastando asimismo con ministros gran parte de su hacienda, como más largamente consta de una información que tiene presentada".

En 1615 sube a Quito con licencia del virrey príncipe de Esquilache para ayudar a las tropas de don Francisco Maldonado en la defensa de Guayaquil y Puerto de la Puná contra el enemigo holandés, "con grande riesgo de la vida, como certifica el dicho general y el príncipe de Esquilache en una certificación que tiene presentada". ${ }^{3}$ Al año siguiente se embarca en el navío San Francisco para el reino de Chile. Según Recio, sólo su valor e industria salvan a este barco del naufragio en una espantosa tormenta

dio al dicho navío una tempestad y tormenta, que quedó desaparejado y hechas pedazos las velas, medio zozobrado más de doce horas, ahogados algunos marineros y el piloto, y los demás perdidas las esperanzas de la vida. Y animándose el dicho maese de campo, tomó el timón en la mano y mandó hacer unas bandolas de los pedazos de vela, con que enderezó el navío. Y aunque de un golpe de timón se le quebró una costilla, no le soltó de la mano en más de cuarenta leguas hasta que entró en el puerto de Valparaíso

\footnotetext{
${ }^{2}$ Ver Historia de la monja alférez. (1838). (Ed.). Joaquín María de Ferrer (cap. II:178-181) y Medina (1963).

${ }^{3}$ Relación de los servicios que Juan Recio de León, sin paginar. Por este motivo, las citas siguientes de este documento irán sin paginar.
} 
Por órdenes secretas del virrey inspecciona los fuertes y guarniciones de Chile y posteriormente soluciona una serie de problemas en la provincia de los pacajes, que no podían cumplir con las obligaciones de las tasas y mitas de Potosí, por la mala organización y abusos que impulsaban a los indios a abandonar la región. Recio actúa de protector de los indios y reorganizador de las mitas haciendo que los españoles paguen a los indios los servicios debidos. También reprime a un contingente de indígenas rebeldes que se refugiaban en la zona, en islas de totoras, y causaban problemas a los demás pobladores: "y con la industria y trazas del maese de campo se hizo el castigo y conquista, poniendo fuego a toda la isla y reduciendo los rebeldes a la iglesia de San Pedro de Cipita, con que cesaron los daños..."

Por estos años interviene varias veces en defensa de los indios, tanto para su protección como para lograr mejores resultados en la producción agrícola y minera, dañada por las fugas de los indios tratados injustamente, como sucedía en Oruro, donde "enteró la mita sin daño de los naturales, haciéndoles asimismo restituir muchas haciendas que los dichos jueces les habían quitado" (loc. cit. sin paginar).

Entre 1619 y 1621 se colocan las actividades más reivindicadas por Recio: los descubrimientos y repoblaciones en Tipuane, Chunchos y Paitites, "la tierra más poderosa de riquezas y naturales que hasta hoy se ha conocido", desempeñando los oficios de maestre de campo, teniente de gobernador, capitán general y justicia mayor, como delegado de Pedro de Leagui Urquiza, gobernador y capitán general de las dichas provincias.

Destaca Recio, en esta etapa, sus exploraciones y refundaciones de las poblaciones de San Juan de Sahagún y Nuestra Señora de Guadalupe, que habían sido abandonadas tras su primera instalación. Construye dos iglesias con pilas bautismales "en donde dos religiosos han bautizado más de 70 señores de provincias, sin otro grande número de almas", y vuelve a insistir en que corre personalmente con los gastos, aludiendo obsesivamente a numerosas certificaciones y testimonios que solicita en todos los lugares de su actuación:

metiendo a su costa y de su hacienda para sustentar ambas vecindades y causar los dichos efectos más de 80 mulas y caballos, con 300 carneros, ${ }^{4}$ todos cargados de bastimentos, ropa, municiones y herramientas, demás de mucho ganado vacuno y ovejuno con que hasta hoy se sustentan todos los sacerdotes y vecinos, en que gastó más de diez mil ducados, y hécholo todo por su mano, como más largamente consta por certificaciones $[\ldots]$ todo lo cual hizo a su costa, pagando indios y demás fletes que se ofrecieron sin agravio de naturales ni españoles, como consta de muchos testimonios que tiene presentados...

\footnotetext{
${ }^{4}$ Estos carneros, que en otra parte llama "carneros de la tierra" (denominación habitual en todos los cronistas) y que cargan con bastimentos, son las llamas.
} 


\section{Ignacio Arellano}

Después de una serie de entradas "en servicio de Dios y de su Majestad", en distintas zonas desde Pelechuco a Uchupiamo y la región — poco definida geográfica y étnicamente - de Chunchos, y asomarse, según sus relatos, a la mítica Paitite, regresa a Lima para solicitar cargos y mercedes, sin recibir atención de las autoridades: "y aunque se ocupó gastando de su hacienda más de 6 meses en hacer las dichas diligencias, no alcanzó ni se le hizo merced más que el avío de cinco religiosos y licencia para venir el dicho maese de campo a España en seguimiento de dicha causa".

\section{RECIO: MEMORIALISTA}

Se habrá advertido en algunos de los pasajes citados, la obsesión de Recio por las certificaciones, informaciones y constancias. En los documentos suyos conservados abundan referencias a otros muchos presentados o testificados relativos a distintos sucesos y servicios. Barnadas ha establecido una lista completa de los impresos, que no son solamente los tres que se suelen mencionar, ${ }^{6}$ sino los siguientes trece que pueden servir para hacerse una idea de la afición de Recio al género

- Los servicios que refiero (Barnadas, núm. 273).

- Breve relación de la descripción y calidad de las tierras y ríos de las provincias de Tipuane... (Barnadas, núm. 274).

- Señor. Relación que Juan Recio de León, maese de campo general... presentó a su Majestad... (Barnadas, núm. 275).

- Relación de los servicios que Juan Recio... ha hecho a su Majestad (Barnadas, núm. 286).

- Señor. Juan Recio de León, natural de la villa de Vega de Rioponce... (Barnadas, núm. 295).

- Señor. Juan Recio de León... a quien Pedro de Leaegui Urquiza... encargó el gasto y peso de los trabajos... (Barnadas, núm. 296).

- Declaración de los ríos... nuevo camino para traer la plata de Potosí (Barnadas, núm. 297).

- Señor. El maese de campo Juan Recio de León dice... para mayor declaración de la verdad del nuevo camino para traer la plata en cuatro meses (Barnadas, núm. 298).

- Señor. El maese de campo Juan Recio de León, natural de la villa de Vega de Ríoponce... propone a vuestra Majestad... (Barnadas, núm. 299).

\footnotetext{
${ }^{5}$ En España sus pretensiones reciben igual acogida, es decir, nula. Solicitaba el oficio de corregidor de Larecaja, o en su defecto, el de los Andes del Cuzco, y algunas otras compensaciones. Tres notas del Consejo (1623-1624-1625) figuran añadidas al memorial que comento: en todas ellas se le remite fríamente al virrey del Perú — de quien nada había conseguido — y se considera que no ha lugar a las compensaciones económicas y ayudas de costa.

${ }^{6}$ Por ejemplo, Glave (1997) 113, № 9, apunta que los memoriales de Recio se conservan en Lima, AGI, 159 y que son tres. Hay más y más ejemplares en otras bibliotecas. Ver Barnadas, núms. 273-275, 286, 295-301, 308-310. Remito a Barnadas para más datos bibliográficos, localización de algunos ejemplares, etc. En el Archivo General de Indias de Sevilla, 70-9-19, se contienen, además de los impresos 273-275, 286 y 301 del repertorio de Barnadas, otra serie de documentos, notas y observaciones del Consejo, y otro memorial manuscrito que empieza "Señor. El maese de campo Juan Recio de León dice que Pedro de Leaegui Urquiza trató con vuestra Majestad y el marqués de Montes Claros, virrey de los reinos del Pirú...”, semejante al impreso núm. 300 de Barnadas. En este trabajo uso fundamentalmente los materiales del AGI sevillano. La mayoría carecen de paginación, pero su extensión permite localizar los pasajes citados sin mucha dificultad. Los identifico a menudo con la numeración en la bibliografía de Barnadas.
} 
- Señor. El maese de campo Juan Recio de León dice que Pedro Leaegui Urquiza capituló... (Barnadas, núm. 300).

- Señor. El maese de campo Juan Recio de León dice que el principal efecto que se sigue a vuestra Majestad... (Barnadas, núm. 301).

- Señor. El maestro de campo Juan Recio de León dice que los indios que de ordinario... (Barnadas, núm. 308).

- Señor. El maese de campo Juan Recio de León dice que la riqueza que se ha sacado del Cerro de Potosí (Barnadas, núm. 309).

- Señor. Juan Recio de León, ma[e]se de campo... como persona que tiene bien entendidas las cosas de los reinos del Pirú... (Barnadas, núm. 310).

De todos ellos comentaré los que me parecen más interesantes en esta oportunidad.

El memorial del que se han extraído los datos biográficos antecedentes permite observar el empeño por certificar documentalmente todo lo que aduce, y la constante ponderación de los gastos que sus empresas le acarrean, motivos constantes en todos sus alegatos. A estos detalles que responden a su perspectiva personal añade otra serie de argumentos que intentan situarse en la perspectiva de la Corona, para convencer a las autoridades competentes de que apoyen sus proyectos.

El escrito "Señor, el maese de campo Juan Recio de León dice que el principal efecto que se sigue a vuestra Majestad..." (Barnadas, núm. 301) propone en cuatro páginas los objetivos principales y los efectos beneficiosos que podrían conseguirse atendiendo a sus reclamaciones. Estos objetivos o efectos se ordenan en dos categorías: por un lado los económicos y políticos (defensa contra los holandeses, acceso a regiones de enormes riquezas de todo tipo, en especial las míticas de Dorado y Paitite, búsqueda de una salida más fácil para la plata de Potosí...), y por otro los religiosos, con la evangelización de los pueblos indígenas, cuyas ansias de conversión asegura Recio en numerosas ocasiones. Hasta ocho efectos importantes atribuye a los descubrimientos - hechos o proyectados - en el citado papel

- Primero: es importante para la evangelización.

- Segundo: en las zonas descubiertas se han refugiado muchos indios huidos del Perú, que abandonan el Evangelio y también los trabajos de mita y otros. Si no se recuperan, corren el riesgo de perderse.

- Tercero: facilita la retención de los pocos indios que quedan en el Perú, y reducción de los ausentes.

- Cuarto: facilita el laboreo de la tierra y la expansión de la ganadería.

- Quinto: permitirá la explotación de innumerables riquezas "de minerales de oro, plata, almendras, cacao, bálsamo, incienso, cañafístola, todo género de especiería, zarzaparrilla, algodón, cochinilla, añil y otros muchos géneros [...]muchas aves y carne de monte y grandiosas pesquerías, que de todo resultará mayor riqueza que del Pirú".

- Sexto: abrir y mantener mejores caminos para llevar la plata del Perú hasta España.

\footnotetext{
${ }^{7}$ Este problema de la despoblación y huida de naturales, con las consecuencias en el trabajo de la mita minera, lo trata en varias partes, y a él le dedica los memoriales y arbitrios listados por Barnadas con los núms., 308-310.
} 


\section{Ignacio Arellano}

- Séptimo: repite el anterior, señalando la mayor facilidad de los viajes. ${ }^{8}$

- Octavo: la población asegura la tierra frente al enemigo holandés.

Por estos motivos, Recio ofrece proseguir con la población que tiene comenzada "y acabar de gastar en ella el resto de la hacienda que le ha quedado en las Indias", para lo cual solicita el cargo de corregidor de Larecaja por seis años, y otras prerrogativas, que no consigue. En el final de este papel suplica el cargo de gobernador de Saña, vacante en el Perú, y se queja de la pobreza en que se encuentra en la Corte.

LA "RELACIÓN QUE JUAN RECIO DE LEÓN... PRESENTÓ A VUESTRA MAJESTAD" Y LA "BREVE RELACIÓN"

Del conjunto de escritos que contemplo en este comentario destacan dos especialmente interesantes por las noticias que aportan sobre el escenario de las empresas del descubridor, tanto por los detalles que añade a sus otros relatos, como por las observaciones sobre la flora, la fauna y las costumbres de los indios.

La primera (núm., 275 de Barnadas) añade algunas precisiones a los datos de la Relación de los servicios. Las ciudades de San Juan de Sahagún y Nuestra Señora de Guadalupe en el valle de Apolobamba habían sido fundadas por don Pedro de Leaegui, pero se despoblaron por falta de bastimentos y otras dificultades. Como señala Armentia (Relación histórica, 1-2), Leaegui comienza sus tareas, penetrando por Camata, en 1615 con 180 hombres y tres agustinos. El 10 de agosto funda Nuestra Señora de Guadalupe.

A principios de 1620, Leaegui nombra a Recio su teniente gobernador y justicia mayor, y le encarga repoblar, lo que hace Recio, según declara, a su costa, gastando "más de veinte mil pesos", entrando con 30 soldados, 25 personas de servicio, 30 mulas y 300 "carneros de la tierra", lo cual "consta por testimonios que presentó de las justicias, curas y escribanos de los dichos pueblos, a foja 22”. En la villa de San Juan de Sahagún tardan un mes con preparativos, y allí acude el cacique Zelipa, señor de todas las provincias de Chunchos, para pedir ayuda contra sus enemigos, a cambio de convertirse con sus gentes al cristianismo. Con la bendición de los religiosos parten tierra adentro ("todo a mi costa, como consta del testimonio del escribano de cabildo de la dicha villa a fol., 29") y alcanzan la junta de los ríos Pelechuco y Chocoata, abriendo varios caminos en el valle de Apolobamba, y sufriendo las emboscadas de los indios lecos y abachiles "apercebidos de armas, arcos, flechas, macanas y rodelas, que ponían espanto, adornados de plumas de guerra". Hacen las amistades con estos indios y alcanzan los cerros de Mapulio y Chipulizani, ricos de oro y de plata. Examinan el mejor sitio para refundar Nuestra Señora de Guadalupe, cosa que se lleva a cabo,

\footnotetext{
${ }^{8}$ Ver el escrito Señor. Juan Recio de León... a quien Pedro de Leaegui Urquiza ... encargó el gasto y peso de los trabajos... (Barnadas, núm., 296) y Declaración de los ríos... nuevo camino para traer la plata de Potosi (Barnadas, núm., 297), o núms., 298 y 299 del repertorio de Barnadas, sobre el mismo asunto.
} 
subrayando Recio su protagonismo, "por lo cual me constituyo y puedo constituir por reedificador de la dicha ciudad y descubridor de las dichas provincias".

Destaca entre otras tareas (descubrimientos y visitas a los pueblos de Uchupiamo y Narama) la construcción de iglesias que permiten bautizar a más de diez mil indios, aunque el cacique Zelipa no había cumplido su palabra de convertirse. Recio Introduce en este punto la narración de la extraordinaria muerte de Zelipa, que se presenta como castigo a su falta. Rozando una montaña golpea con su hachuela de oro un árbol, que "contra toda naturaleza, del peso de arriba se cayó contra él y le mató, haciéndole dos pedazos". El extraordinario suceso impulsa una tanda de conversiones, y abandonan en las citadas provincias de los Chunchos las guacas, ídolos y prácticas paganas, bautizándose en masa.

Recio prosigue con su tropa atravesando las provincias de los paramonas, arabaonas y otras tribus de las riberas del Diabeni (el actual río Beni), perseguidos en ocasiones, "comiendo hierbas del campo silvestres y bebiendo algunos días de nuestros propios orines", hasta que consiguen amistar con los naturales, con eficaz diplomacia y regalos.

Nuevas empresas que le encarga el gobernador resultan imposibles por el obstáculo de los ríos desbordados, pero llegan noticias del Paitite, legendario territorio semejante al Dorado, y se preparan nuevas expediciones.

Sin embargo, las aventuras de Recio parecen haber llegado a su final. Cuando viaja a Lima para reclutar sus capitanes y soldados no tiene éxito. Reclama al virrey cargos y autoridad para la empresa, presentando memorial tras memorial, informaciones, descripciones de la riqueza y calidad de la tierra... Recaba el apoyo de teólogos y misioneros, y se ofrece a pagar de su costa "todos los fletes y gastos". Todo en vano. Parte a Madrid para seguir sus pretensiones en la Corte, donde, como ya se ha visto, no le irá mejor. De sus peticiones al rey (corregimiento de Larecaja, cien sacerdotes, doscientos mil ducados de socorro, 200 mosquetes, 300 arcabuces, etc.) ni siquiera consigue ayuda de costa para sus necesidades en Madrid.

Adjunta a esta relación una nueva lista que sintetiza los servicios de la jornada y pacificación, donde se recogen los hechos consignados en el documento 286 de Barnadas.

La Breve relación (documento núm., 274 de Barnadas, también de 1623) me parece la más interesante de todas las versiones de los trabajos de Recio de León, por añadir una serie de noticias de valor etnográfico y antropológico sobre las provincias de Tipuane, Chunchos y otras "del grande reino del Paitite", constituyendo, entre otras cosas, "valiosos documentos que abundan en detalles referentes a plantas y animales, sus costumbres y usos asociados, a principios del siglo XVII en una región del norte de Bolivia" (Arellano Torres, 2011:43). Para Barnadas (I, 208) $)^{9}$ se trata de una relación "interesantísima y una de las más

\footnotetext{
${ }^{9}$ Hay una versión manuscrita en la Biblioteca Nacional de España, ms., 3.826, fols., 87r-93v.
} 


\section{Ignacio Arellano}

antiguas descripciones geográficas y etnográficas del piedemonte amazónico (la provincia histórica de Laricaja y el país de los Chunchos)".

La Breve relación tiene una primera parte que recoge algunos datos que figuran en otros memoriales de Recio, como la apertura de caminos de San Juan de Sahagún a las juntas de los ríos Pelechuco y Chocoata, o la travesía del río Toiche (actual Tuichi) en callapos ("Pasé en balsas estas juntas"). Introduce explicaciones de términos ("tiene nombre de Diabeni, que en lengua de los naturales quiere decir junta de las muchas aguas"), y da una serie de noticias sobre la red hidrográfica, no siempre reconocibles con precisión: el río Magno, que algunos identifican con el Beni, quizá por ofrecer Recio la misma explicación del nombre ("de aquí para adelante le dan los naturales nombre de Magno, que en su lengua quiere decir junta de muchas aguas") tiene que ser otro distinto, pues desemboca en el mismo Beni ("entra en el Toiche y Diabeni unas 20 leguas más al nordeste de la junta de los dos dichos"); probablemente se refiera al Manú, que recibe en otro tramo el nombre de Mapiri, el cual desemboca en el Beni. ${ }^{10}$ Presta atención especial a los productos vegetales y animales, ponderando la abundancia y calidad de las riquezas de la zona en que se mueve, recurriendo con mucha frecuencia al léxico

Esta montaña clara tiene la mayor cantidad de los árboles de canela, nuez moscada, nogales de Castilla, cañafístola, bálsamo, incienso, guayacán y cacao en mucha abundancia; [...] mucho maíz, frijoles, pallares, camotes, yuca, zapallo y otras muchas legumbres que la tierra produce; tienen muchísimas frutas: plátanos, guayabas, lúcumas, pitahayas, añonis, mameyes, muchos palmitos y dátiles, caña dulce; no tienen ganados domésticos pero hay grandes manadas de puercos que llaman saínos, que naturaleza les puso el ombligo en el lomo; andan en manadas de 100 y 200 y son de condición que al más pequeño de toda la manada siguen todos como a su capitán, y si alguna persona hiere o mata alguno, si tan presto no se sube en un árbol o se asegura, lo hacen pedazos los demás, pero poniéndose en alto con un chuzo los puede matar a todos si es que no acierten a matar el capitanejo, porque en sintiéndole muerto o herido desamparan todos el puesto tan violentamente como si tuvieran alas. Hay también a las orillas de los ríos otro género de puercos que llaman guardatinajas, hay muchas antas y venados, monos, micos, cuyes, osos, leoncillos de poca fiereza, en partes hay algunos tígueres, que es el animal más bravo que hay en estas partes; no tienen gallinas ni aves de Castilla ni otras mansas excepto patos, pero hay muchas pavas de las que en España llaman gallinas de las Indias silvestres, en todas las montañas; hay también muchos paujíes, que es otro género de aves mayores y de mayor regalo que las pavas; muchas guacamayas, guacharacas, torcaces, tórtolas, papagayos, perdices y otros muchos géneros de aves de diversas colores, gozan también de maravillosos pescados de estos ríos, que los conocidos por

\footnotetext{
${ }^{10} \mathrm{La}$ red fluvial ofrece innumerables problemas a los descubridores y viajeros posteriores, por la complejidad de las corrientes en esta parte de la cuenca amazónica. Ver Armentia (1887). Lo mismo sucede con las tribus de indios y sus asentamientos.
} 
sus nombres son estos: sábalos, róbalos, pataloes, sollos, bagres, doncellas y otros muchos diferentes que los de España.

Nótese la frecuencia del léxico regional (lúcumas, pitahayas, añonis, cuyes, guacharacas, paujies...), que aumenta en la descripción de los ritos y costumbres. En ocasiones se aplica el nombre a una especie semejante, aunque distinta, a la conocida en Europa.

Habla Recio, también, de la exquisita miel ("Hay en todas las montañas dichas muchísima miel de abejas, bonísima y muy blanca"), que se puede identificar con el producto de las abejas Meliponidae.

Disemina Recio, en esta relación, numerosos detalles sobre las construcciones (los grandes galpones de los indios marapa, en los que viven 100 y 200 juntos; las casas de palo y palma en las provincias montuosas de los chunchos, menicos y taranos; los grandes poblados de a dos y a tres mil casas de tapia y adobe, con puertas y ventanas de madera toscamente labradas, y cubiertas de paja en la provincia de los marquires, lindante con el Paitite, etc.), vestidos y adornos (uso de la pampanilla ${ }^{11}$ por los marquires solteros, aunque la mayoría visten algodón; manillas de oro en las muñecas y otras en las gargantas de los pies de las mujeres, chagualas colgadas de las narices y orejas), armas (macanas, arcos y flechas, cerbatanas con dardos envenenados, hachuelas de oro como insignia de los caciques)

Da detalles de la organización política y social, los ritos de boda, de guerra o funerales: se gobiernan generalmente con caciques, en los llanos "cuando se ha de tener uno por casado con una mujer no hay más concierto que dar el novio un vestido al suegro y otro a la suegra, y si la moza no tiene padres al pariente más cercano, y con esto se la lleva a su casa"; celebran las batallas con diversas ceremonias y borracheras:

Cuando tienen guerra con sus enemigos, después de haber acabado la batalla se juntan todos en la plaza junto a una casa de comunidad donde tienen en depósito muy grande número de armas y el ídolo en que adoran, y sacan el ídolo y le ponen en medio de la plaza y junto a él al señor y también con ellos al que se mostró más valiente en la batalla; donde todos danzan, celebran su fiesta y hacen muchas borracheras de muchas bebidas que todos acostumbran a hacer de maíz, yuca, batata, almendra y otras muchas legumbres, y habiendo acabado la fiesta ofrecen al ídolo, al señor y al valiente, por iguales partes, muchos pedacillos de ídolos de oro, plata y otros metales, conforme cada uno puede.

Muchas de estas ceremonias, como los ritos funerales, Recio los atribuye a imitación de los del Perú, ya que considera a los pobladores de las cercanías del mítico Paitite descendientes de los ejércitos del Inca que ingresaron en la región:

\footnotetext{
${ }^{11}$ pampanilla: taparrabos; las chagualas, según el DRAE, son pendientes que los indios llevaban en la nariz —otros léxicos los consideran collares - pero Recio lo aplica, también, a los de las orejas. No anoto, en general, los indigenismos sobre los que hay abundante bibliografía.
} 


\section{Ignacio Arellano}

Cuando muere algún principal le ponen en medio de la plaza y sacan de la guaca el ídolo y le ponen junto a él y todos traen allí las bebidas que tienen en su casa, y hasta que las acaban de beber no llevan el cuerpo a la sepultura. El uso de la sepultura es que tienen en el campo de cada linaje un torreón muy alto de ladrillo o adobe y por de dentro una escalera volteada; y allí, puestos, donde ponen los cuerpos difuntos de aquel linaje, que hoy día están tan enteros los más de ellos como hoy hace mil años cuando allí los metieron, que basta para entender que es la tierra más sana del mundo. Con esos cuerpos los días del entierro algunos ídolos de oro y plata ofrecen a su usanza.

Le interesa también la organización religiosa, de la que menciona los sacerdotes, chamanes o moanes, cuya condición idólatra subraya comparándolos con los sacerdotes del dios Bel, ídolo de Babilonia equivalente del cananeo Baal. Los engaños de los sacerdotes de Bel los puso al descubierto el profeta Daniel (Daniel, 14), episodio que seguramente evoca Recio en su texto

un moan, al modo del sacerdote del ídolo Bel que favorecido del demonio los engaña y le obedecen más que a las cabezas principales, o por mejor decir le temen más; este tal, cuando los indios temen que han de tener guerra con algunos enemigos o tienen necesidad de que llueva para sus sementeras, se va a la guaca y oráculo donde tienen los ídolos en que adoran, como que habla con el sopay, ${ }^{12}$ que no lo dudo, porque es el diablo, y les dice lo que le parece que basta para que le adoren...

Conforme la trayectoria se acerca (imaginariamente sobre todo) a los territorios que se identifican con el Paitite se adensan los elementos legendarios. Es significativo que en el centro de este espacio mítico esté una gran laguna, poblada de islas, como sucede en muchas otras regiones fabulosas. ${ }^{13}$

Por las cercanías viven los guarayos, que son caníbales ("son caribes, comen carne humana"), y en los confines del Paitite existe una provincia de amazonas

Diéronme también noticia que de la banda del norte de este río Apurima, confines del Paitite, estaba una provincia de mujeres que viven sin hombres, y preguntándoles cómo podían conservarse de aquella manera dijeron que hombres tenían en la otra banda del Paitite al este de que darían más razón los Marquires que confinan con ellos...

Recio, como otros muchos cronistas, no puede resistir la atracción de la leyenda de las amazonas, constantemente reiterada en el Siglo de Oro, mezcladas las historias de la antigüedad con las crónicas de Indias. Por razones obvias, uno de los que más atención presta al mito es Cristóbal de Acuña en su Nuevo descubrimiento del gran río de las Amazonas. Claro es que no todos los cronistas

\footnotetext{
${ }^{12}$ Especie de diablo andino. Recio usa el vocablo quechua.

${ }^{13}$ Sobre la importancia de la condición insular, las lagunas o los grandes ríos en la conformación de los espacios maravillosos, ver Pellicer (2010).
} 
aceptan a las amazonas con esta credulidad. Aguilar, por ejemplo, escribe en $E l$ Marañón, lib. I, cap., 10:

cayeron en error los españoles que le llamaron ansí solo por haber visto en él mujeres con arcos y flechas que peleaban, siendo común entre muchas naciones bárbaras pelear también las mujeres y usar de flechas y arco en nuestro tiempo.

López de Gómara (139) también se burló de esta hablilla de las amazonas.

Recio no sólo recoge las noticias que le dan los guarayos de las amazonas, sino otra más curiosa de los marquires sobre una provincia de hombres solos: "entre ellos y la laguna del Paitite dijeron que estaba una provincia de hombres sin mujeres; y preguntándoles que cómo aquellos hombres vivían sin mujeres, respondieron que dos meses al año las tenían y que de otra parte por aquellas aguas venían a juntarse con ellos". Entre los marquires hay también algunos especímenes extraordinarios "tan rubios que son cortos de vista", albinos sin duda.

FINAL

Los escritos de Recio poseen, pues, a mi juicio, un doble interés. Por una parte reflejan la trayectoria personal de un descubridor de mediana entidad, con proyectos más modestos de lo que quiere aparentar, y con un contraste notable (como les sucede a tantos otros, empezando por el mismo Cristóbal Colón) entre aspiraciones y premios, servicios y reconocimientos. Por otra, ofrecen una serie de noticias de una zona que no abunda en descripciones semejantes de la época. Los datos geográficos, históricos y etnográficos que aporta Recio en el área del Madidi y cuenca amazónica del Beni constituyen un notable testimonio del estado de la región en el primer tercio del siglo XVII. Y en el trasfondo la fascinación por el mito, la búsqueda de la maravilla en territorios llamados el Dorado o Paititi, lugares de fabulosas riquezas y seres extraordinarios. Desde el primer momento Recio es utilizado como fuente de información. Ya Antonio de León Pinelo en su Memoria de los papeles que tengo para la descripción de las Indias, lista una Relación de las provincias de Tipuane y Paitite, que puede referirse a cualquiera de las dos últimas que he comentado (Baudot, 1968). Más tarde sus textos se acumularán a otros argumentos en las disputas territoriales entre Perú, Argentina y Bolivia (Saavedra, 1910; Maurtúa, 1907).

No se conoce, sin embargo, en tiempos recientes una edición ordenada de sus diversos memoriales y relaciones. Aunque no constituyan uno de los ejemplos más relevantes del inmenso corpus textual generado por los descubrimientos, es sin duda imprescindible para el acercamiento a las realidades y a las imágenes de la región de Larecaja y valle de Apolobamba.

Universidad de Navarra*

Grupo de Investigación Siglo de Oro (GRISO)

Campus universitario $s / n$

31009 Pamplona-Navarra (España)

iarellano@unav.es 
Ignacio Arellano

\section{BIBLIOGRAFÍA}

Acosta, José de. Historia natural y moral de las Indias [Sevilla, Juan de León, 1590]. (Ed.). Fermín del Pino. Madrid: CSIC, 2008.

Acuña, Cristóbal de. Nuevo descubrimiento del gran río de las Amazonas. (Ed.). Ignacio Arellano, José María Díez Borque y Gonzalo Santonja. Madrid: Iberoamericana, 2009.

Aguilar y Córdoba, Diego de. El Marañón. (Ed.). Julián Díez Torres. Madrid: Iberoamericana, 2011.

Arellano Torres, Gabriel. "Plantas en la Breve relación del capitán Juan Recio de León, 1623", en Discursos coloniales. Texto y poder en la América hispana, ed. P. Latasa. Madrid: Iberoamericana, 2011: 43-53.

Armentia, Nicolás. Relación histórica de las misiones franciscanas de Apolobamba. La Paz: Imprenta del Estado, 1903.

------ Navegación del Madre de Dios. La Paz: Imprenta de la Paz, 1887.

Barnadas, Josep. Bibliotheca boliviana antiqua. Sucre: Fundación Cultural del Banco Central de Bolivia / Archivo y Biblioteca Nacionales de Bolivia / Centro de Estudios Bolivianos Avanzados, 2 vols., 2008.

Baudot, Georges. "La Memoria de Antonio de León Pinelo: unos títulos de historiografía mexicana", en Historia Mexicana, 18.2. 1968:227-243.

Erauso, Catalina de. Historia de la monja alférez, Catalina de Erauso, escrita por ella misma. (Ed.). Ángel Esteban. Madrid: Cátedra, 2006.

------ Historia de la monja alférez. (Ed.). Joaquín María Ferrer. Barcelona: José Tauló, 1838.

Fernández de Oviedo, Gonzalo. Sumario de la natural historia de las Indias. (Ed.). Álvaro Baraibar. Madrid: Iberoamericana, 2010.

Glave, Luis Miguel. "Santa Rosa de Lima y sus espinas: la emergencia de mentalidades urbanas de crisis y la sociedad andina", en Manifestaciones religiosas en el mundo colonial americano. (Ed.). Clara García Ayluardo y Manuel Ramos Medina. México: Universidad Iberoamericana, 1997:109-128.

López de Gómara, Francisco. Historia general de la Indias. (Ed.). Pilar Guibelalde. Barcelona: Orbis, 1985.

Maurtúa, Víctor Manuel. Juicio de límites entre el Perú y Bolivia. Barcelona: Heinrich y Co., 1907.

------ Juicio de límites entre el Perú y Bolivia. Tomo sexto. Misiones centrales peruanas. Buenos Aires: Compañía Sudamericana de Billetes de Banco, 1907.

Medina, José Toribio. Biblioteca hispano chilena (1523-1817). Santiago de Chile: Casa del autor, 1963.

Pellicer, Rosa. "Espacios imaginarios del Nuevo Mundo en la literatura española del Siglo de Oro", en Parnaso de dos mundos. De literatura española e hispanoamericana en el Siglo de Oro. Madrid: Iberoamericana, 2010:455-477.

Saavedra, Bautista. Defensa de los derechos de Bolivia. Buenos Aires: Talleres de la casa Jacobo Peuser, 1910. 